\title{
An optimal policy for deteriorating items with time-proportional deterioration rate and constant and time-dependent linear demand rate
}

\author{
Trailokyanath Singh ${ }^{1} \cdot$ Pandit Jagatananda Mishra $^{2} \cdot$ Hadibandhu Pattanayak $^{2}$
}

Received: 7 October 2016/Accepted: 17 March 2017/Published online: 6 April 2017

(C) The Author(s) 2017. This article is an open access publication

\begin{abstract}
In this paper, an economic order quantity (EOQ) inventory model for a deteriorating item is developed with the following characteristics:

(i) The demand rate is deterministic and two-staged, i.e., it is constant in first part of the cycle and linear function of time in the second part.

(ii) Deterioration rate is time-proportional.

(iii) Shortages are not allowed to occur.
\end{abstract}

The optimal cycle time and the optimal order quantity have been derived by minimizing the total average cost. A simple solution procedure is provided to illustrate the proposed model. The article concludes with a numerical example and sensitivity analysis of various parameters as illustrations of the theoretical results.

Keywords Constant and time-dependent linear demand rate $\cdot$ Deteriorating items $\cdot$ EOQ $\cdot$ Time-proportional deterioration rate.

Mathematics Subject Classification 90B05

Trailokyanath Singh

trailokyanaths108@gmail.com

Pandit Jagatananda Mishra

pjmishramath@gmail.com

Hadibandhu Pattanayak

h.pattnayak@gmail.com

1 Department of Mathematics, C. V. Raman College of Engineering, Bhubaneswar, Odisha 752054, India

2 Department of Mathematics, Ravenshaw University, Cuttack, Odisha 753003, India

\section{Introduction}

Most of the business organizations emphasize on inventory management and solving inventory problems because they want to obtain economic order quantity (EOQ) which minimizes the total average inventory cost. Over the last few decades, many researches have been done for controlling and maintaining the inventory. In real life situation, decay or deterioration of items is a natural phenomenon. Vegetables, fruits, foods, perfumes, chemicals, pharmaceutical, radioactive substances and electronic equipments, etc., are examples of deteriorating items, i.e., the loss characteristics of items at any time is regarded as deterioration. Therefore, it is not wise to ignore the factor deterioration while analyzing the model. Several inventory models for deteriorating items are developed to answer these questions: "How much to order to replenish the inventory of an item" and "When to order so as to minimize the total cost" (Gupta and Hira 2002).

The classical inventory model for deteriorating items of Harris (1915) and Wilson (1934) states that the depletion of inventory is mainly due to the constant demand rate. Firstly, the effect of deterioration on fashion items after their prescribed date was studied by Whitin (1957). Later, a dynamic version of the classical EOQ model for deteriorating items was developed by Wagner and Whitin (1958). Ghare and Schrader (1963) studied the inventory model for deteriorating items with constant deterioration rate and constant demand rate with the help of the differential equation $\frac{\mathrm{d} I(t)}{\mathrm{d} t}=-\theta I(t)-D(t), \quad 0 \leq t \leq T$ where $I(t), D(t)$ and $\theta$ represent the inventory level at any time $t$, the demand rate at time $t$ and constant deterioration rate, respectively, during the cycle time $T$. Furthermore, the model for replenishment policies involving time-varying 
pattern has received much attention from several researchers. Donaldson (1977) examined the classical noshortage inventory model for deteriorating items with a linear trend in demand over a known and finite horizon by using calculus method. An order-level inventory model for deteriorating items having constant deterioration rate was studied by Shah and Jaiswal (1977). Aggarwal (1978) modified the work of Shah and Jaiswal by calculating the average holding cost. Dave and Patel (1981) developed the inventory model for deteriorating items with linear increasing in demand rate and deterioration rate which was a constant fraction of the on-hand inventory. All the models discussed above are based on the constant deterioration rate, constant demand rate, infinite replenishment and no shortage. Heng et al. (1991) proposed an exponential decay in inventory model for deteriorating items by assuming a finite replenishment rate and constant demand rate. The reviews of the advances of deteriorating inventory literature are presented by Raafat (1991); Goyal and Giri (2001); Li et al. (2010); Bakker et al. (2012) and Janssen et al. 2016).

Goswami and Chaudhuri (1991) considered the replenishment policy for a deteriorating item with linear trend in demand rate. $\mathrm{Xu}$ et al. (1991) presented an inventory model for deteriorating items with linear demand rate over known and finite horizon. Chung and Ting (1994) proposed a heuristic inventory model for deteriorating items with time-proportional demand rate. Wee (1995) proposed a replenishment policy with exponential time-varying demand rate by extending the partial backlogging model. Benkherouf (1995) presented an optimal replenishment policy for a deteriorating item with known and finite planning horizon. The above models are based on constant deterioration rate and shortages. Srivastava and Gupta (2007) studied an EOQ model for deteriorating items with constant deterioration rate, both the constant and time-dependent demand rate and no-shortages.

In the real market situation, the state of demand rate of any product is always dynamic. Many researchers developed models by assuming time-dependent demand as linear, quadratic or exponential. However, linear demand, quadratic demand and exponential demand rates require uniform change, steady increase or decrease and rapid changes in demand rate, respectively. Chakrabarti and Chaudhuri (1997) studied a replenishment inventory problem for a deteriorating item over finite horizon with linear trend in demand rate. Singh and Pattnayak (2014) presented a two-warehouse inventory model with conditionally permissible delay in payment by considering linear demand rate. Ghosh and Chaudhuri (2004) developed an inventory model with two-parameter Weibull distribution deterioration rate, time-quadratic demand rate and shortages. Khanra et al. (2011) discussed an order-level inventory model for a deteriorating item with time-dependent quadratic demand rate and constant deterioration rate. The inventory models for deteriorating items with constant deterioration rate and exponential demand rate are established by Hollter and Mak (1983) and Ouyang et al. 2005).

Some more researches have been carried out on quantity discount, partial back-ordering, fuzzy environment of inventory system and delay in payments, etc. Widyadana et al. (2011) solved two EOQ models for deteriorating items inventory problems without using derivatives and found these as almost similar to the original model. Taleizadeh et al. (2013) solved a fuzzy rough EOQ model for deteriorating items considering quantity discount and prepayment by using meta-heuristic algorithms. Taleizadeh (2014) established an EOQ model for an evaporating item with partial back-ordering and partial consecutive prepayments. In this model, the retailers are allowed to pay all or a fraction of cost in advance. Thangam (2014) developed a two-level trade credit financing with selling price discount and partial order cancelations under permissible delay in payment. Taleizadeh et al. (2015) developed a production and inventory problem under two scenarios in a three-layer supply chain which involves one distributor, one manufacturer and one retailer. In this model, both defective items and raw materials with imperfect quality are sold at lower prices. Heydari and Norouzinasab (2015) studied a two-level discount inventory model for coordinating a decentralized supply chain considering demand as stochastic and price-sensitive.

Another class of researches on inventory model for deteriorating items was developed by considering the deterioration rate as time-proportional. Covert and Philip (1973) derived an EOQ model for deteriorating items without shortages under the condition of constant demand rate and two-parameter Weibull distribution deterioration rate. Philip (1974) generalized the model of Covert and Philip with same conditions by replacing two-parameter Weibull distribution by three-parameter Weibull distribution deterioration rate. Misra (1975) suggested an optimum production lot size inventory model for deteriorating items by including both constant and varying deterioration rate. Ghosh and Chaudhuri (2006) developed an EOQ model for a deteriorating item over a finite time-horizon by considering quadratic demand rate, time-proportional deterioration rate and by allowing shortages in all cycles. Mishra et al. (2013) developed an inventory model for deteriorating items with time-proportional deterioration rate, timedependent linear demand rate and time-varying holding cost under partial backlogging. Sarkar and Sarkar (2013) considered an inventory model with variable deterioration rate and inventory dependent demand rate. Sanni and Chukwu (2013) developed an EOQ model for deteriorating 
items with ramp-type demand rate, three-parameter Weibull distribution deterioration after allowing shortages.

In classical inventory models, the deterioration rate and demand rate are assumed to be constant. But in reality, the demand is constant for some period of time and then it increases or decreases according to the popularity of the product. Furthermore, time is most important factor which plays an important role in developing the inventory model. As failure rate of some items increases with the passage of time, then the deterioration rate increases with respect to time. Therefore, the time-proportional deterioration rate is more realistic for the development of the model.

In this paper, an EOQ inventory model for deteriorating items is developed with time-proportional deterioration rate as well as both the constant and time-dependent linear demand rate. The demand for such products is constant for some time and after that, when the product becomes popular in the market, the demand for the product increases. A situation like this commonly occurs in practice. Shortages are not allowed to occur. The reason for considering the time-proportional deterioration rate and constant and time-dependent demand rate is due to the change in deterioration rate with respect to time and the suitable demand for the present market situation, respectively. It is assumed that items do not deteriorate at the beginning of the period, but the deterioration rate is time-proportional after some time with an increase in demand. The reason for considering constant and timedependent demand rate instead of the time-dependent demand is due to the newly launched products like new branded android mobiles, automobiles, garments, etc. The demand for such products becomes constant initially and then increases. Shortages are not allowed to occur. In addition, the time-proportional deterioration rate is considered for the change in deterioration rate with respect to the time. The main objective of the model is to minimize the average total cost by optimizing the cycle time point. In addition, optimal order quantity is calculated. The solution procedure backed by a numerical example is provided to illustrate the proposed model. Finally, sensitivity of the solution with respect to various parameters associated with the model is studied.

The rest of the paper is organized as follows: the assumptions and notations for the development of the model are provided in Sects. 2 and 3, respectively. The formulation of the model is described in Sect. 4. In Sects. 5 and 6 , solution procedure and a numerical example are presented to illustrate the developed model. In Sect. 7, sensitivity analysis with respect to various parameters is carried out. Finally, the summary and the future direction of research are given in Sect. 8.

\section{Assumptions}

To develop the proposed mathematical model of the inventory system, the following assumptions are considered in this paper:

(i) The inventory system involves only one type of item.

(ii) There is no deterioration for the first part of the cycle and the deterioration rate is time-proportional for the second part of the cycle.

(iii) The demand is deterministic and has a twocomponent form for the time horizon, i.e., it is constant for the part of the cycle and is a linear function of time in the second part of the cycle.

(iv) Shortages are not allowed to occur.

(v) The occurrence of replenishment is instantaneous and the delivery lead time is zero.

(vi) The planning horizon is infinite. Only a typical planning schedule of length is considered and all the remaining cycles are identical.

(vii) Deteriorated units are not replaced or repaired during the cycle period under consideration.

(viii) The ordering cost, holding cost and unit cost remain constant over time.

\section{Notations}

For convenience, the following notations are used throughout the paper.

$\theta(t)$ : The time-proportional deterioration rate, i.e., $\theta(t)=\theta_{0} t$, where $0<\theta_{0}<<1$ and $t>0$. For $t=1$, the time-proportional deterioration rate reduces to a constant deterioration rate.

$D(t)$ : The varying demand rate, i.e.,

$$
D(t)= \begin{cases}a, & 0 \leq t \leq \mu \\ a+b(t-\mu), & \mu \leq t \leq T .\end{cases}
$$

During the first interval $[0, \mu]$, the demand is constant at the rate of $a$ units per unit time, i.e., it does not vary with time and during the second interval $[\mu, T]$, the demand rate is a linear function of time.
$\mathrm{I}(\mathrm{t})$ :
The inventory level at any time $t$.
$T$ :
The length of the replenishment cycle.
$q$ :
The number of items received at beginning of the inventory system.
$c_{\mathrm{o}}$ : The ordering cost per order. 
$h_{\mathrm{c}}$ : $\quad$ The inventory holding cost per unit per unit of time.

$d_{\mathrm{c}}$ : $\quad$ The unit cost of the item per unit per unit of time.

$\mu$ : $\quad$ The time point at which the demand increases with time as well as the deterioration starts.

ATC $(T): \quad$ The average total cost per unit per unit time.

$T^{*}$ : $\quad$ The optimal value of $T$.

$q^{*}$ : $\quad$ The optimal value of $q$.

$\operatorname{ATC}\left(T^{*}\right)$ : The optimal average total cost per unit per unit time.

\section{Mathematical formulation of the model}

The cycle starts with the initial lot-size $q$ at time $t=0$. During the time $[0, \mu]$, the inventory level decreases due to the constant demand rate, say, $a$ units per unit time. At time $t=\mu$, the depletion occurs due to the combined effect of demand and deterioration and finally comes to an end at time $t=T$. The behavior of the inventory system is depicted in the Fig. 1.

The objective of the model is to determine the optimal cycle length $T$ that minimizes the average total cost $\operatorname{ATC}(T)$ over the time horizon $[0, T]$.

During the interval $[0, \mu]$, the demand rate is constant per unit time and is given by

$a$

and thus, the total demand in the interval $[0, \mu]$ is given by

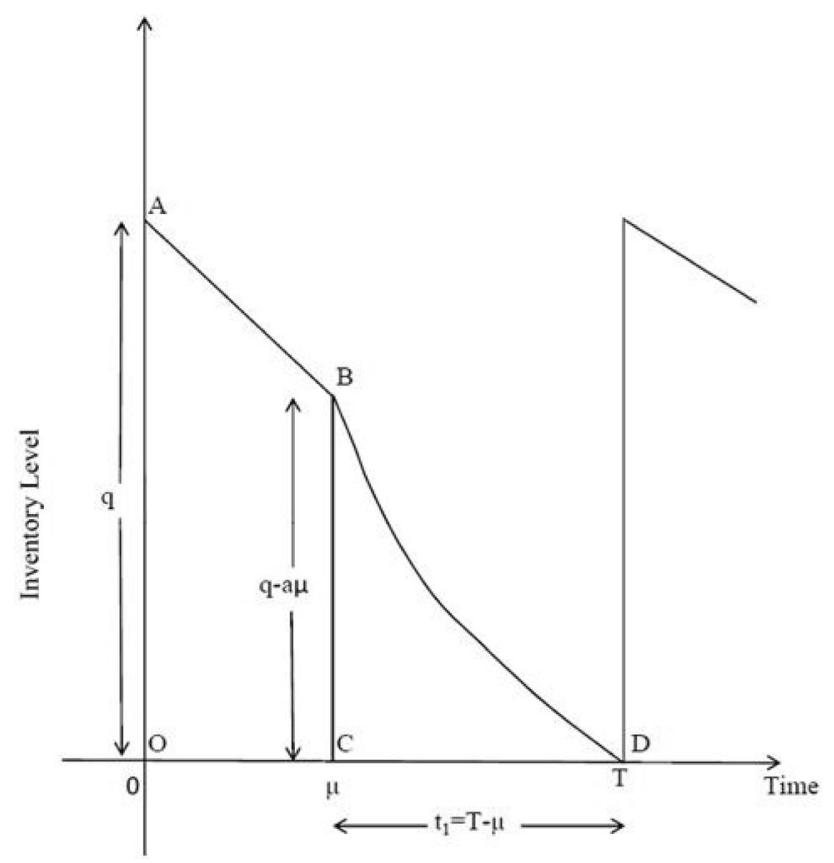

Fig. 1 The graphical representation of the inventory level with time $a \mu$.

Therefore, the inventory level is reduced by the factor $a \mu$ and thus, the rest of inventory during $[\mu, T]$ is given by

$q-a \mu$.

For the sake of mathematical simplicity, the interval $[\mu, T]$ can be written as

$t_{1}=T-\mu$.

During the period $[\mu, T]$, the instantaneous inventory level $I(t)$ at any time $t$ is governed by the following differential equation:

$\frac{\mathrm{d} I(t)}{\mathrm{d} t}+\theta(t) I(t)=-[a+b(t-\mu)], \quad 0 \leq t \leq t_{1}$,

where $\theta(t)=\theta_{0} t, \quad\left(0<\theta_{0}<<1\right)$.

The solution of the differential Eq. (4.1) with boundary condition $I(0)=q-a \mu$ is given by

$I(t)=\left[q-a \mu-a\left(t+\frac{\theta_{0} t^{3}}{6}\right)-b\left[\frac{t^{2}}{2}+\frac{\theta_{0} t^{4}}{8}-\mu\left(t+\frac{\theta_{0} t^{3}}{6}\right)\right]\right] e^{-\frac{\theta_{0} t^{2}}{2}}, 0 \leq t \leq t_{1}$,

by neglecting the higher power of $\theta_{0}$ as $0<\theta_{0}<<1$.

The Eq. (4.6) at $I\left(t_{1}\right)=0$ is given by

$q=a \mu+a\left(t_{1}+\frac{\theta_{0} t_{1}^{3}}{6}\right)+b\left[\frac{t_{1}^{2}}{2}+\frac{\theta_{0} t_{1}^{4}}{8}-\mu\left(t_{1}+\frac{\theta_{0} t_{1}^{3}}{6}\right)\right]$.

According to the assumptions of the model, the average total cost is composed of the following costs:

I. The ordering cost (IOC):

$\mathrm{IOC}=c_{\mathrm{o}}$

II. The inventory holding cost (IHC) during the period $[0, T]$ is calculated as follows:

1. The of inventory holding cost during the period $[0, \mu]$ is $h_{\mathrm{c}} \times$ area of trapezium $\mathrm{ABCO}$, i.e.,

$$
\begin{gathered}
h_{\mathrm{c}}\left[\frac{1}{2} \times(q+(q-a \mu)) \times \mu\right] \\
=\mu h_{\mathrm{c}}\left[(q-a \mu)+\frac{a \mu}{2}\right]
\end{gathered}
$$

and

2. The inventory holding cost during the period $\left[0, t_{1}\right]$ is $h_{\mathrm{c}} \times$ area of triangle $\mathrm{BDC}$, i.e.,

$$
=h_{\mathrm{c}}\left[\frac{1}{2} \times t_{1} \times(q-a \mu)\right] \text {. }
$$

Thus, the inventory holding cost (IHC) during the period $[0, T]$ is the sum of inventory holding cost 
during the period $[0, \mu]$ and inventory holding cost during the period $\left[0, t_{1}\right]$, i.e.,

$$
\mathrm{IHC}=h_{\mathrm{c}}\left[\frac{a \mu^{2}}{2}+(q-a \mu)\left(\mu+\frac{t_{1}}{2}\right)\right] .
$$

III. The deterioration cost (IDC) during the period $[0, T]$ is

$$
\begin{aligned}
\mathrm{IDC} & =d_{\mathrm{c}}\left[q-a \mu-\int_{0}^{t_{1}}[a+b(t-\mu)] \mathrm{d} t\right] \\
& =d_{\mathrm{c}}\left[q-a \mu-(a-b \mu) t_{1}-\frac{b t_{1}^{2}}{2}\right] .
\end{aligned}
$$

Hence, the average total cost per unit time $(\operatorname{ATC}(T))$ of the system during the period $[0, T]$ expressed as the sum of the ordering cost, the inventory holding cost and the deterioration cost, i.e.,

$$
\begin{aligned}
\operatorname{ATC}(T)= & \frac{1}{T}[\mathrm{IOC}+\mathrm{IHC}+\mathrm{IDC}] \\
= & \frac{c_{\mathrm{o}}}{T}+\frac{a(T-\mu)}{T}\left[1+\frac{\theta_{0}(T-\mu)^{2}}{6}\right]\left[\frac{h_{\mathrm{c}}(T+\mu)}{2}+d_{\mathrm{c}}\right] \\
& +\frac{b(T-\mu)}{T}\left[\frac{(T-\mu)}{2}+\frac{\theta_{0}(T-\mu)^{3}}{8}-\mu-\frac{\mu \theta_{0}(T-\mu)^{2}}{6}\right] \\
& \times\left[\frac{h_{\mathrm{c}}(T+\mu)}{2}+d_{\mathrm{c}}\right] \\
& +\frac{1}{T}\left[\frac{h_{\mathrm{c}} a \mu^{2}}{2}-d_{\mathrm{c}}(a-b \mu)(T-\mu)-\frac{b d_{\mathrm{c}}(T-\mu)^{2}}{2}\right],
\end{aligned}
$$

by using Eqs. (4.4) and (4.7)

The objective of the problem is to determine the optimal value of $T$, i.e., $T^{*}$ such that $\operatorname{ATC}(T)$ is minimum.

For the optimum value of $\operatorname{ATC}(T)$, we have

$$
\frac{\partial \operatorname{ATC}(T)}{\partial T}=0
$$

and

$$
\frac{\partial^{2} \operatorname{ATC}(T)}{\partial T^{2}}>0
$$

From Eq. (4.14), we have

$$
\begin{aligned}
\frac{\partial \mathrm{ATC}(T)}{\partial T} & =\frac{a}{T}\left[1+\frac{\theta_{0}(T-\mu)^{2}}{2}\right]\left[\frac{h_{\mathrm{c}}(T+\mu)}{2}+d_{\mathrm{c}}\right] \\
& +\frac{b}{T}\left[T-2 \mu+\frac{\theta_{0}(T-\mu)^{3}}{2}-\frac{\mu \theta_{0}(T-\mu)^{2}}{2}\right]\left[\frac{h_{\mathrm{c}}(T+\mu)}{2}+d_{\mathrm{c}}\right] \\
& +\frac{a h_{\mathrm{c}}(T-\mu)}{2 T}\left(1+\frac{\theta_{0}(T-\mu)^{2}}{6}\right) \\
& +\frac{b h_{\mathrm{c}}(T-\mu)}{2 T}\left(\frac{(T-\mu)}{2}+\frac{\theta_{0}(T-\mu)^{3}}{8}-\mu-\frac{\mu \theta_{0}(T-\mu)^{2}}{6}\right) \\
& -\frac{1}{T}\left[d_{\mathrm{c}}(a-b \mu)+b d_{\mathrm{c}}(T-\mu)+\operatorname{ATC}(T)\right]=0
\end{aligned}
$$

provided the sufficient condition

$$
\frac{\partial^{2} \mathrm{ATC}(T)}{\partial T^{2}}>0
$$

(See Appendix).

The solution procedure for above described model is given below.

\section{Solution procedure: algorithms}

To obtain the optimal value of $A T C(T)$ and $q$, the following steps are adopted.

Step I. Put the appropriate value of the parameters.

Step II. Determine the value of $T$ from the Eq. (4.16) by Newton-Raphson method.

Step III. Compare $T$ with $\mu$.

(i) If $T>\mu$, then $T$ is a feasible solution, say $T^{*}$. Go to Step IV.

(ii) If $T<\mu$, then $T$ is infeasible.

Step IV. Substitute $T^{*}$ in Eqs. (4.13) and (4.7) to get $\operatorname{ATC}\left(T^{*}\right)$ and $q^{*}$, respectively.

\section{Numerical example}

To illustrate the results obtained from the inventory model for deteriorating items with two-component demand rate and time-proportional deterioration rate, the following numerical example is considered.

Example 1 Let us take the parametric values of the inventory model of deteriorating items in their units as follows:

$h_{\mathrm{c}}=\$ 0.50 /$ unit $/$ day $, \quad c_{\mathrm{o}}=\$ 80.0, \quad d_{\mathrm{c}}=\$ 18.0 /$ unit, $a=20$ units, $b=0.2, \mu=0.4$ days and $\theta_{0}=0.02$.

Solving Eq. (4.16), the optimal cycle time is $T^{*}=$ 2.73841 days which satisfies the sufficient condition, i.e., $\frac{\partial^{2} \mathrm{ATC}\left(T^{*}\right)}{\partial T^{2}}=10.5991>0$. Substituting the value of $T^{*}=$ 2.73841 in Eqs. (4.13) and (4.7), the optimal value of the average total cost and the optimal order quantity are $\operatorname{ATC}\left(T^{*}\right)=\$ 48.9359$ and $q^{*}=55.9919$ units, respectively.

\section{Sensitivity analysis}

We now study the effect of changes in the values of various parameters $c_{\mathrm{h}}, c_{\mathrm{o}}, d_{\mathrm{c}}, a, b, \mu$ and $\theta_{0}$ on the optimum cost and optimum order quantity. The sensitivity analysis is performed by changing the each of the parameters by +50 , 
Table 1 Sensitivity analysis

\begin{tabular}{|c|c|c|c|c|c|c|}
\hline Parameter & $\begin{array}{l}\% \text { Change } \\
\text { in parameter }\end{array}$ & $T^{*}$ & $\operatorname{ATC}\left(T^{*}\right)$ & $\begin{array}{l}\% \text { Change in parameter } \\
\operatorname{ATC}\left(T^{*}\right)\end{array}$ & $q^{*}$ & $\begin{array}{l}\% \text { Change in } \\
\text { parameter } q^{*}\end{array}$ \\
\hline \multirow[t]{6}{*}{$h_{c}$} & +50 & 2.50948 & 55.6374 & +13.8036 & 51.0990 & -08.73859 \\
\hline & +25 & 2.64076 & 51.6908 & +05.62961 & 53.8977 & -03.74018 \\
\hline & +10 & 2.68848 & 50.3265 & +02.84168 & 54.9198 & -01.91474 \\
\hline & -10 & 2.79070 & 47.5175 & -02.89849 & 57.1179 & +02.01101 \\
\hline & -25 & 2.84550 & 46.0702 & -05.85603 & 58.3014 & +04.12470 \\
\hline & -50 & 3.02688 & 51.5378 & -15.11790 & 62.2449 & +11.16770 \\
\hline \multirow[t]{6}{*}{$c_{0}$} & +50 & 3.17443 & 62.4447 & +27.60510 & 65.4841 & +16.95280 \\
\hline & +25 & 2.92744 & 54.5820 & +11.53770 & 60.0778 & +07.29731 \\
\hline & +10 & 2.83584 & 51.8060 & +05.86502 & 58.0925 & +03.75161 \\
\hline & -10 & 2.63416 & 45.9581 & -06.085100 & 53.7565 & -03.99236 \\
\hline & -25 & 2.52177 & 42.8553 & -12.425600 & 51.3602 & -08.27209 \\
\hline & -50 & 2.11418 & 32.5224 & -33.540800 & 42.7791 & -23.59770 \\
\hline \multirow[t]{6}{*}{$d_{c}$} & +50 & 2.53320 & 51.4989 & +5.23746 & 51.6033 & -07.83792 \\
\hline & +25 & 2.64703 & 50.0231 & +2.22168 & 54.0318 & -03.50068 \\
\hline & +10 & 2.69087 & 49.4912 & +1.13475 & 54.9710 & -01.82330 \\
\hline & -10 & 2.79024 & 48.3544 & -1.18829 & 57.1080 & +01.99332 \\
\hline & -25 & 2.84712 & 47.7438 & -2.43604 & 58.3364 & +04.18721 \\
\hline & -50 & 3.05928 & 45.6933 & -6.62622 & 62.9537 & +12.43360 \\
\hline \multirow[t]{6}{*}{$a$} & +50 & 2.36117 & 57.6703 & +17.84870 & 71.8225 & +28.27300 \\
\hline & +25 & 2.56327 & 52.6566 & +07.60321 & 62.6315 & +11.85810 \\
\hline & +10 & 2.64573 & 50.8408 & +03.89264 & 59.3710 & +06.03498 \\
\hline & -10 & 2.84374 & 46.9277 & -04.10374 & 52.4786 & -06.27466 \\
\hline & -25 & 2.96504 & 44.7982 & -08.45535 & 48.8106 & -12.82560 \\
\hline & -50 & 3.48469 & 37.3961 & -23.58150 & 36.5675 & -34.69140 \\
\hline \multirow[t]{6}{*}{$b$} & +50 & 2.72798 & 49.2064 & +0.184936 & 55.9512 & -0.072689 \\
\hline & +25 & 2.73421 & 48.9722 & +0.074179 & 55.9756 & -0.029111 \\
\hline & +10 & 2.73630 & 48.9541 & +0.037191 & 55.9836 & -0.014824 \\
\hline & -10 & 2.74053 & 48.9176 & -0.037396 & 56.0003 & +0.015002 \\
\hline & -25 & 2.74265 & 48.8993 & -0.074792 & 56.0085 & +0.029647 \\
\hline & -50 & 2.74910 & 48.8442 & -0.187388 & 56.0340 & +0.075189 \\
\hline \multirow[t]{6}{*}{$\mu$} & +50 & 2.81508 & 47.4662 & -3.003320 & 57.2587 & +2.262470 \\
\hline & +25 & 2.76874 & 48.3248 & -1.248780 & 56.4881 & +0.886200 \\
\hline & +10 & 2.75351 & 48.6263 & -0.632660 & 56.2380 & +0.439528 \\
\hline & -10 & 2.72343 & 49.2535 & +0.649012 & 55.7496 & -0.432741 \\
\hline & -25 & 2.70857 & 49.5795 & +1.315190 & 55.5109 & -0.859053 \\
\hline & -50 & 2.66478 & 50.6088 & +3.418550 & 54.8192 & -2.094410 \\
\hline \multirow[t]{6}{*}{$\theta_{0}$} & +50 & 2.52401 & 51.5931 & +5.42996 & 51.7311 & -07.60967 \\
\hline & +25 & 2.64227 & 50.0671 & +2.31160 & 54.0822 & -03.41067 \\
\hline & +10 & 2.68825 & 49.5145 & +1.18236 & 54.9958 & -01.77901 \\
\hline & -10 & 2.79349 & 48.3280 & -1.24224 & 57.0854 & +01.95296 \\
\hline & -25 & 2.85444 & 47.6870 & -2.55211 & 58.2948 & +04.11292 \\
\hline & -50 & 3.08764 & 45.5104 & -6.99997 & 62.9177 & +12.36930 \\
\hline
\end{tabular}

$+25,+10,-10,-25$ and $-50 \%$ taking one parameter at a time and keeping remaining parameters unchanged. The analysis is based on Example 1 and the results are shown in Table 1. The following points are observed. (i) $\quad T^{*}$ increases while $\operatorname{ATC}\left(T^{*}\right)$ and $q^{*}$ decrease with the increase in the value of the parameter $h_{\mathrm{c}}$. Here $T^{*}, \operatorname{ATC}\left(T^{*}\right)$ and $q^{*}$ are moderately sensitive to changes in $h_{\mathrm{c}}$. 
Table 2 Effect of parameter $\mu$ on optimal policies

\begin{tabular}{lllll}
\hline$\mu$ & Change $(\%)$ in $\mu$ & $T^{*}$ & $\operatorname{ATC}\left(T^{*}\right)$ & $q^{*}$ \\
\hline 0.05 & -87.5 & $2.61179(-4.62385 \%)$ & $52.0100(+6.28189 \%)$ & $54.0083(-3.54266 \%)$ \\
0.10 & -75 & $2.62923(-3.98699 \%)$ & $51.5283(+5.29754 \%)$ & $54.2717(-3.07223 \%)$ \\
0.50 & +25 & $2.77639(+1.13869 \%)$ & $48.1769(-1.55101 \%)$ & $56.6143(+1.11159 \%)$ \\
1.00 & +150 & $2.97597(+8.67511 \%)$ & $45.0588(-7.92281 \%)$ & $60.0315(+7.21461 \%)$ \\
2.00 & +400 & $3.40395(+24.3039 \%)$ & $41.4160(-15.3668 \%)$ & $67.8973(+21.2627 \%)$ \\
3.00 & +650 & $3.82521(+39.6873 \%)$ & $40.0379(-18.1830 \%)$ & $76.1137(+35.9370 \%)$ \\
4.00 & +900 & $4.14838(+51.4886 \%)$ & $39.9703(-18.3211 \%)$ & $82.8513(+47.9702 \%)$ \\
4.10 & +925 & $4.16699(+52.1682 \%)$ & $40.0065(-18.2471 \%)$ & $83.2853(+48.7453 \%)$ \\
4.20 & +950 & 4.18098 & $\ldots$ & $\ldots$ \\
4.30 & +975 & 4.18921 & $\ldots$ & $\ldots$ \\
4.40 & +1000 & 1.42505 & $\ldots$ & $\ldots$ \\
4.50 & +1025 & 1.78138 & $\ldots$ & $\ldots$ \\
\hline
\end{tabular}

Here '...' denotes the infeasible solution (ii) $T^{*}, \operatorname{ATC}\left(T^{*}\right)$ and $q^{*}$ increase with the increase in the value of the parameter $c_{0}$. Here $T^{*}, \operatorname{ATC}\left(T^{*}\right)$ and $q^{*}$ are highly sensitive to changes in $c_{\mathrm{o}}$.

(iii) $T^{*}$ and $q^{*}$ decrease while $\operatorname{ATC}\left(T^{*}\right)$ increases with the increase in the value of the parameter $d_{\mathrm{c}}$. Here $T^{*}, \operatorname{ATC}\left(T^{*}\right)$ and $q^{*}$ are moderately sensitive to changes in $d_{\mathrm{c}}$.

(iv) $\quad T^{*}$ decreases while $\operatorname{ATC}\left(T^{*}\right)$ and $q^{*}$ increase with the increase in the value of the parameter $a$. Here $T^{*}, \operatorname{ATC}\left(T^{*}\right)$ and $q^{*}$ are highly sensitive to changes in $a$.

(v) $\quad T^{*}$ and $q^{*}$ decrease while $\operatorname{ATC}\left(T^{*}\right)$ increases with the increase in the value of the parameter $b$ and $\theta_{0}$. Here $T^{*}, \operatorname{ATC}\left(T^{*}\right)$ and $q^{*}$ have low sensitivity to changes in $b$ and $\theta_{0}$.

(vi) $\quad T^{*}$ and $q^{*}$ increase while $\operatorname{ATC}\left(T^{*}\right)$ decreases with the increase in the value of the parameter $\mu$. Here $T^{*}, \operatorname{ATC}\left(T^{*}\right)$ and $q^{*}$ have low sensitivity to changes in $\mu$.

From Table 2: It reveals that if the parameter $\mu$ is decreased by $87.5 \%$, then the value of the optimal cycle time decreases by $4.62385 \%$, the optimal average total cost increases by $6.28189 \%$ and the optimal order quantity decreases by $3.54266 \%$. Further, if the parameter $\mu$ is increased by $925 \%$, then the value of the optimal cycle time increases by $52.1682 \%$, the optimal average total cost decreases by $18.2471 \%$ and the optimal order quantity increases by $48.7453 \%$.

The notable point is that the increase in the value of the parameter $\mu$ after $\mu=4.10$ gives infeasible solution as $\mu>T$.

\section{Conclusion}

In this paper, an EOQ inventory model is developed for a deteriorating item with the two-staged demand rate, that is, it is constant at first part of the cycle and linear function of time at the second part of the cycle. The reason for considering constant and time-dependent linear demand rate is due to the newly launched products like new branded android mobiles, automobiles, garments, etc. The demand for such products remains constant initially and then increases. When a new product is launched in the market, the demand for such product becomes constant for some time and after that the demand increases due to the popularity of the product. Moreover, the time-proportional deterioration rate may be valid for the items whose deterioration rate changes with respect to time. It is assumed that items do not deteriorate at the beginning of the period, but after sometime, the deterioration rate increases with time. Deterioration rate is time-proportional. Shortages are not allowed to occur. The optimal cycle time and the optimal order quantity have been derived by minimizing the total average cost. A simple solution procedure is provided to illustrate the proposed model. The article is concluded with a numerical example and a sensitivity analysis of various parameters to support the theoretical results.

The proposed model can be extended in several ways. Firstly, we may extend the linear demand to a more generalized pattern that fluctuates with time, price or stockdemand rate. This idea can be extended for stochastic demand pattern too. Secondly, we could extend the model 
to variable deterioration rates like the two-parameter Weibull distribution deterioration rate and Gamma distribution deterioration rate. Finally, we could extend it by incorporating the concept of shortages or partial backlogging.

Acknowledgements The authors would like to thank the editor and anonymous reviewers for their valuable comments and suggestions, which improved the presentation of the paper.

Open Access This article is distributed under the terms of the Creative Commons Attribution 4.0 International License (http://crea tivecommons.org/licenses/by/4.0/), which permits unrestricted use, distribution, and reproduction in any medium, provided you give appropriate credit to the original author(s) and the source, provide a link to the Creative Commons license, and indicate if changes were made.

\section{Appendix}

$$
\begin{aligned}
& \frac{\partial^{2} \mathrm{ATC}(T)}{\partial T^{2}}=\frac{1}{T}\left[a \theta_{0}(T-\mu)+b\left(1+\frac{3 \theta_{0}(T-\mu)^{2}}{2}-\mu \theta_{0}(T-\mu)\right)\right] \\
& \times\left[\frac{h_{\mathrm{c}}(T+\mu)}{2}+d_{\mathrm{c}}\right] \\
& +\frac{h_{\mathrm{c}}}{T}\left[a\left(1+\frac{\theta_{0}(T-\mu)^{2}}{2}\right)+b\left(T-2 \mu+\frac{\theta_{0}(T-\mu)^{3}}{2}-\frac{\mu \theta_{0}(T-\mu)^{2}}{2}\right)\right]-\frac{b d_{\mathrm{c}}}{T} \\
& -\frac{2}{T^{2}}\left[a\left(1+\frac{\theta_{0}(T-\mu)^{2}}{2}\right)+b\left(T-2 \mu+\frac{\theta_{0}(T-\mu)^{3}}{2}-\frac{\mu \theta_{0}(T-\mu)^{2}}{2}\right)\right] \\
& \times\left[\frac{h_{\mathrm{c}}(T+\mu)}{2}+d_{\mathrm{c}}\right] \\
& -\frac{h_{\mathrm{c}}(T-\mu)}{T^{2}}\left[a\left(1+\frac{\theta_{0}(T-\mu)^{2}}{6}\right)+b\left(\frac{(T-\mu)}{2}+\frac{\theta_{0}(T-\mu)^{3}}{8}-\mu-\frac{\mu \theta_{0}(T-\mu)^{2}}{6}\right)\right] \\
& +\frac{2 d_{\mathrm{c}}}{T^{2}}[a+b(T-2 \mu)]+\frac{2(T-\mu)}{T^{3}}\left[a\left(1+\frac{\theta_{0}(T-\mu)^{2}}{6}\right)\right. \\
& \left.+b\left(\frac{(T-\mu)}{2}+\frac{\theta_{0}(T-\mu)^{3}}{8}-\mu-\frac{\mu \theta_{0}(T-\mu)^{2}}{6}\right)\right]\left[\frac{h_{\mathrm{c}}(T+\mu)}{2}+d_{\mathrm{c}}\right] \\
& +\frac{2}{T^{3}}\left[\frac{h_{\mathrm{c}} a \mu^{2}}{2}-d_{\mathrm{c}}(a-b \mu)(T-\mu)-\frac{b d_{\mathrm{c}}(T-\mu)^{2}}{2}+\mathrm{ATC}(T)\right] .
\end{aligned}
$$

\section{References}

Aggarwal SP (1978) A note on an order-level inventory model for a system with constant rate of deterioration. Opsearch 15:184-187

Bakker M, Riezebos J, Teunter RH (2012) Review of inventory systems with deterioration since 2001. Eur J Oper Res 221:275-284

Benkherouf L (1995) On an inventory model with deteriorating items and decreasing time-varying demand and shortages. Eur J Oper Res 86:293-299

Chakrabarti T, Chaudhuri KS (1997) An EOQ model for deteriorating items with a linear trend in demand and shortages in all cycles. Int J Prod Econ 49:205-213
Chung KJ, Ting PS (1994) On replenishment schedule for deteriorating items with time-proportional demand. Prod Plan Control 5:392-396

Covert RP, Philip GC (1973) An EOQ model for items with Weibull distribution deterioration. AIIE Trans 5:323-326

Dave U, Patel LK (1981) (T, Si) policy inventory model for deteriorating items with time proportional demand. J Oper Res Soc 32:137-142

Donaldson WA (1977) Inventory replenishment policy for a linear trend in demand-an analytical solution. J Oper Res Soc 28:663-670

Ghare PM, Schrader GF (1963) A model for exponentially decaying inventory. J Ind Eng 14:238-243

Ghosh SK, Chaudhuri KS (2006) An EOQ with a quadratic demand, time-proportional deterioration and shortages in all cycles. Int $\mathrm{J}$ Syst Sci 37:663-672

Ghosh SK, Chaudhuri KS (2004) An order-level inventory model for a deteriorating item with Weibull distribution deterioration, time-quadratic demand and shortages. Adv Model Optim 6:21-35

Goswami A, Chaudhuri KS (1991) An EOQ model for deteriorating items with shortages and a linear trend in demand. J Oper Res Soc 42:1105-1110

Goyal SK, Giri BC (2001) Recent trends in modeling of deteriorating inventory. Eur J Oper Res 134:1-16

Gupta PK, Hira DS (2002) Operation research. S. Chand \& Company LTD, New Delhi

Harris FW (1915) Operations and costs. A. W. Shaw Company, Chicago

Heng KJ, Labban J, Linn RJ (1991) An order-level lot-size inventory model for deteriorating items with finite replenishment rate. Comput Ind Eng 20:187-197

Heydari J, Norouzinasab Y (2015) A two-level discount model for coordinating a decentralized supply chain considering stochastic price-sensitive demand. J Ind Eng Int 11:531-542

Hollter RH, Mak KL (1983) Inventory replenishment policies for deteriorating items in a declining market. Int $\mathrm{J}$ Prod Res 21:813-836

Janssen L, Claus T, Sauer J (2016) Literature review of deteriorating inventory models by key topics from 2012 to 2015. Int J Prod Econ 182:86-112

Khanra S, Ghosh SK, Chaudhuri KS (2011) An EOQ model for a deteriorating item with time dependent quadratic demand under permissible delay in payment. Appl Math Comput 218:1-9

Li R, Lan H, Mawhinney JR (2010) A review on deteriorating inventory study. J Serv Sci Manag 3:117-129

Mishra VK, Singh LS, Kumar R (2013) An inventory model for deteriorating items with time-dependent demand and timevarying holding cost under partial backlogging. J Ind Eng Int 9:1-5

Misra RB (1975) Optimum production lot size model for a system with deteriorating inventory. Int J Prod Res 13:495-505

Ouyang LY, Wu KS, Cheng MC (2005) An inventory model for deteriorating items with exponential declining demand and partial backlogging. Yugosl J Oper Res 15:277-288

Philip GC (1974) A generalized EOQ model for items with Weibull distribution deterioration. AIIE Trans 6:159-162

Raafat F (1991) Survey of literature on continuously deteriorating inventory models. J Oper Res Soc 42:27-37

Sanni SS, Chukwu WIE (2013) An economic order quantity model for items with three-parameter Weibull distribution deterioration, ramp-type demand and shortages. Appl Math Model 37:9698-9706

Sarkar B, Sarkar S (2013) Variable deterioration and demand-an inventory model. Econ Model 31:548-556 
Shah YK, Jaiswal MC (1977) An order-level inventory model for a system with constant rate of deterioration. Opsearch 14:174-184

Singh T, Pattnayak H (2014) A two-warehouse inventory model for deteriorating items with linear demand under conditionally permissible delay in payment. Int $\mathbf{J}$ Manag Sci Eng Manag 9:104-113

Srivastava M, Gupta R (2007) EOQ Model for deteriorating items having constant and time-dependent demand rate. Opsearch 44:251-260

Taleizadeh AA (2014) An EOQ model with partial backordering and advance payments for an evaporating item. Int J Prod Econ 155:185-193

Taleizadeh AA, Noori-daryan M, Tavakkoli-Moghaddam R (2015) Pricing and ordering decisions in a supply chain with imperfect quality items and inspection under buyback of defective items. Int J Prod Res 53:4553-4582

Taleizadeh AA, Wee HM, Jolai F (2013) Revisiting a fuzzy rough economic order quantity model for deteriorating items considering quantity discount and prepayment. Math Comput Model $57: 1466-1479$
Thangam A (2014) Retailer's inventory system in a two-level trade credit financing with selling price discount and partial order cancelations. J Ind Eng Int 10:1-12

Wagner HM, Whitin TM (1958) Dynamic version of the economic lot size model. Manage Sci 5:89-96

Wee HM (1995) A deterministic lot-size inventory model for deteriorating items with shortages and a declining market. Comput Oper Res 22:345-356

Whitin TM (1957) The theory of inventory management, 2nd edn. Princeton University Press, Princeton

Wilson RH (1934) A scientific routine for stock control. Harv Bus Rev 13:116128

Widyadana GA, Crdenas-Barrn LE, Wee HM (2011) Economic order quantity model for deteriorating items with planned backorder level. Math Comput Model 54:1569-1575

Xu H, Wang HPB (1991) An economic ordering policy model for deteriorating items with time proportional demand. Eur J Oper Res 46:21-27 